\title{
A PROPOSED INTENSE SLOW POSITRON SOURCE BASED ON ${ }^{58} \mathrm{Co}$
}

\author{
Benjamin L. Brown \\ Mount Holyoke College \\ Art Denison and Henry Makowitz \\ INEL \\ Dave Gidley, Bill Frieze, Henry Griffin, and Pedro Encarnación \\ University of Michigan
}

Abstract

Positron beams have proven very useful for condensed matter and surface research. The highest intensity of the current operating positron beams is $-10^{4}$ slow $\mathrm{e}^{+} / \mathrm{second}$. The goal of our proposal is to build an Intense Slow Positron Source (ISPS) demonstration beam (Phase I) of unprecedented brightness at the Idaho National Engineering Laboratory, INEL (up to $10^{10}$ slow $\mathrm{e}^{+} / \mathrm{s}$ at $5 \mathrm{keV}$ over a $<0.03 \mathrm{~cm}$. diameter). This Phase I beam will prove the principles necessary to build a larger facility scale ISPS Phase II beam which will have a potential of $10^{13} \mathrm{e}^{+} / \mathrm{s}$, or $>10^{12} \mathrm{e}^{+} / \mathrm{s}$ over $0.03 \mathrm{~cm}$. The INEL is an ideal location for the ISPS because of the fast breeder reactor EBR-II, which is perfectly suited to creating the positron emitting isotope ${ }^{58} \mathrm{Co}$, and the excellent radioactive materials handling capability and expertise. Sufficient scientific expertise is available at INEL for the construction and operation of a user facility (Phase II).

Prepared for U. S. Department of Energy through the EG\&G Idaho, Inc. LDRD program. Under DOE-ID Contract DE-AC07-76ID01570 


\section{ISPS BEAM OVERVIEW}

The principles associated with the INEL Intense Slow Positron Source have already been demonstrated on a "small" scale (i.e., $\leq 1 \mathrm{~cm}^{2}$ ) by the positron physics community and by commercial isotope producers in the case of the ${ }^{58} \mathrm{Co}$ production. The INEL proposes to scale up this technology, by several orders of magnitude, using available hot cells, etc., and to build a special demonstration beam facility. Refer to Figure 1. Concurrent to this three-year ISPS device development effort, a "Super-Microscope" will be designed by the Michigan Group. The INEL Experimental Breeder Reactor (EBR II) has ample fast neutrons and is ideally suited to efficient ${ }^{58} \mathrm{Co}$ production. INEL also has previous experience in handling high levels of radioactive material.

We are currently proposing a demonstration scale (Phase I) intense slow positron source, ISPS, device which will achieve a monoenergetic positron beam of $\sim 10^{10} \mathrm{e}^{+} / \mathrm{s}$ at $5 \mathrm{keV}$ on a $\leq 0.03$-cm-diameter target using a ${ }^{58} \mathrm{Co}$. This trial beam will represent a significant advancement over beams now available. One preeminent purpose of the positron beam will be the development of a super microscope and user facility which will obtain the ultimate possible resolution of a positron reemission microscope. We shall refer to this demonstration beam as Phase I ISPS, to distinguish it from Phase II beam (including a microscope/microprobe) that would be designed based on what is learned during the Phase I project.

The positron microscope ${ }^{1-3}$ opens up the possibility of a high resolution electron type microscope that has several differing qualities relative to the electron counterpart. An advantage to positrons is the extreme sensitivity to lattice imperfections and voids which can be exploited using Doppler broadening and angular correlation techniques. Another novel technique involves the examination of surface conditions using reemission microscopy ${ }^{4.5}$ The potential resolution is $10 \AA$ and the ultimate positron beam strength is $\sim 1$ $\mu \mathrm{A}$. A combination electron and positron microscope would find applications in the basic research and technological development of solid materials, interfaces, surfaces, liquids, and a host of other applications including the study of biological molecules. A scanning intense positron beam for angular correlation of annihilation radiation would find applications in materials research, defects studies, surfaces and interfaces. The microelectronics industry has expressed strong interest in this facility and other industries will benefit from this technology. A recent meeting, held by the Department of Energy in Palm Springs CA, in September 1992, was devoted to exploring various applications of intense positron beams. Several additional possible 


\section{ISPS Phase I Beam}

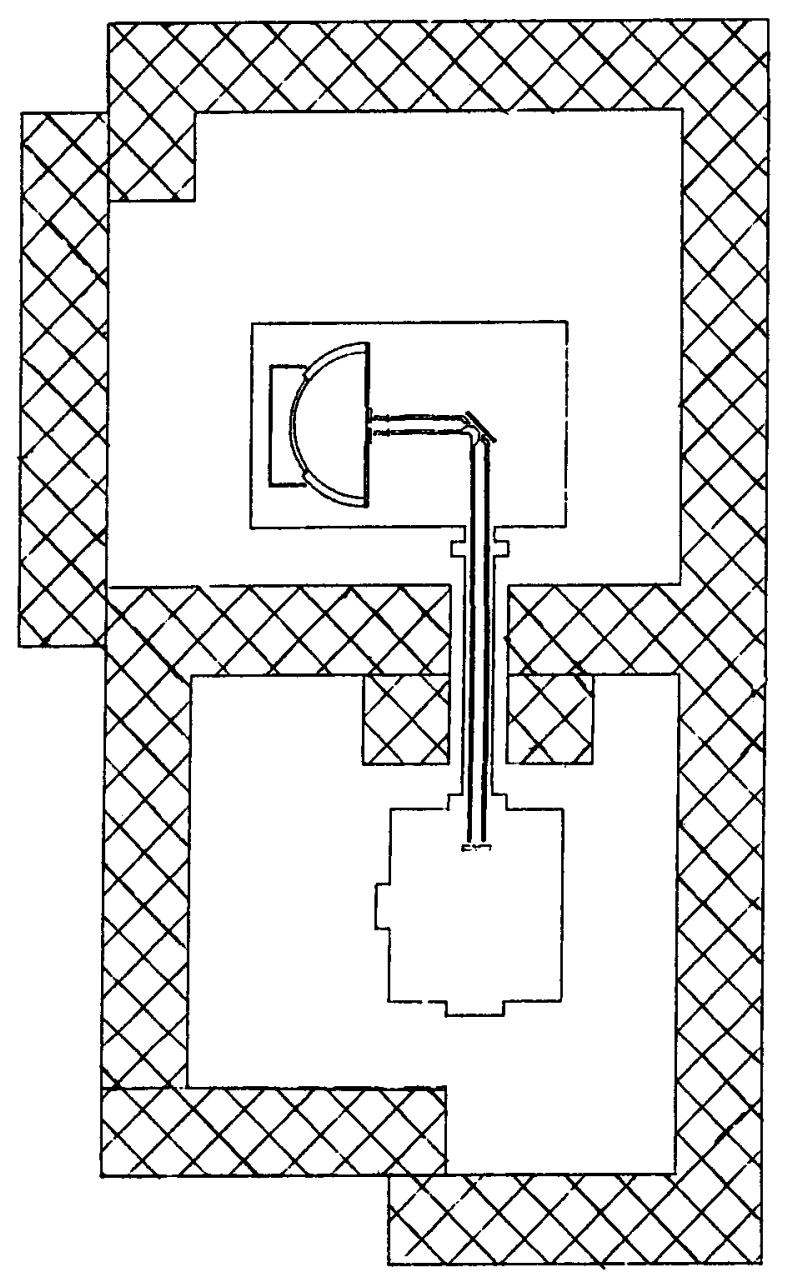

$K{ }_{1 \text { meter }} Y$

FIGURE 1 INTENSE SLOW POSITRON SOURCE (ISPS DEVICE) BASED ON ${ }^{58} \mathrm{Co}$. THE SOURCE IS PLATED ON A HEMISPHERICAL SURFACE, AND Ne IS DEPOSITED ON THE SURFACE TO PROVIDE EFFICIENT MODERATION OF THE POSITRONS. 
applications were detailed at this meeting. There is no doubt that an intense positron beam would be of considerable interest not only to the positron community ${ }^{6}$ but to many outside the present community. The Japanese positron physics community has managed to find several techniques that are adaptable to industrial and process control applications. We hope this type interface with industry can eventually be developed in this country.

Positrons are created by beta decay of ${ }^{58} \mathrm{Co}$ plated ${ }^{7}$ on the inner side of a spherical surface (spherical segment) that forms a dish shape. We refer to this as the source dish. Refer to Figure 2. The beam, in the latest design configuration, consists of the following: a $30 \mathrm{~cm}$ diameter positron source; a neon solid moderator; a $\mathrm{W}$ thin crystal remoderator; and appropriate electrostatic optics. ${ }^{8}{ }^{58} \mathrm{Ni}$ bombarded by neutrons in a hard flux nuclear reactor creates ${ }^{58} \mathrm{Co}$, a $\beta^{+}$emitter. Chemical separation of the ${ }^{58} \mathrm{Co}$, from the ${ }^{58} \mathrm{Ni}$, followed by electroplating of the ${ }^{58} \mathrm{Co}$ onto part of the dish area (10's of $\mathrm{cm}^{2}$ for Phase I) produces a source with a minimum of self absorption. ${ }^{7}$ The positrons are produced with a broad energy spectrum with an endpoint energy of $474 \mathrm{keV}$. A fraction of positrons $\left(\leq 10^{-2}\right)$ are reemitted from the neon rare gas solid moderator at low energy at $\sim 1 \mathrm{eV}$. These "slow" positrons are accelerated to $5 \mathrm{keV}$ and focused onto a W single crystal foil remoderator. ${ }^{8} \mathrm{~A}$ large fraction $(\leq 0.35)$ are reemitted through the thin moderator at low energy, due to the negative positron work function. The solid angle of emission is somewhat narrow and the positrons emerge with the characteristic W work function energy, $\sim 2.5 \mathrm{eV}$. The energy loss in the foil increases the brightness of the beam (brightness enhancement ${ }^{t}$ ) enabling a subsequent reduction in beam size. A beam diameter reduction of $\sim 35 \mathrm{x}$ is achieved for each remoderation step and the acceleration remoderation step is repeated until the resulting beam diameter is reduced to the desired size.

\section{ISPS PHASE I BEAM DEVELOPMENT}

The Idaho National Engineering Laboratory (INEL), the University of Michigan and Mount Holyoke College have agreed to jointly pursue a Super Positron Microscope Facility to be located at the INEL. The beam development will begin with a 3 year Phase I proof of principle program.

During Year One of the program, in collaboration with Michigan, a $\leq 15 \mathrm{Ci}{ }^{58} \mathrm{Co}$ room temperature source will be developed for use with the existing microscope in Ann Arbor. The University of Michigan research reactor will be used to irradiate $\mathrm{Ni}$ samples and the separation chemistry and plating technology will be explored. This will allow the INEL to gain experience in the chemical separation of ${ }^{58} \mathrm{Co}$ and demonstration ISPS device. Mount Holyoke College will develop the cryogenic Ne thin film technology. Design of the cryogenic system for eventual Ne moderation will take place at Mount Holyoke. The choice of the isotope ${ }^{58} \mathrm{Co}$ has been made partly because 
B. L. Brown et al. 293

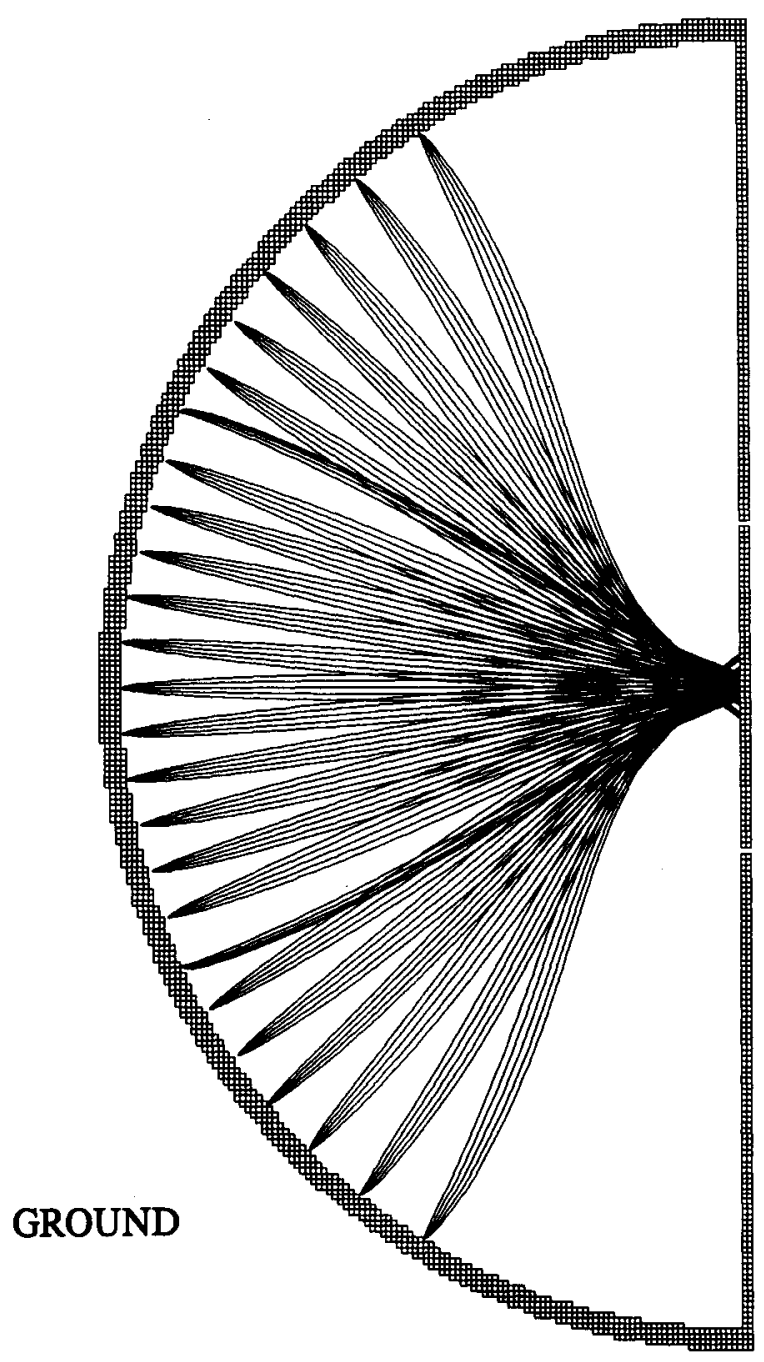

GROUND

$-5 \mathrm{Kv}$

REMODERATOR

$-5 \mathrm{Kv}$

GROUND

FIGURE 2 Positron emission from a hemispherical surface, as simulated by SIMION. The disk on the right is biased at $-5 \mathrm{kV}$; all other surfaces are grounded. The positrons are assumed to be emitted at high energies and then moderated by a thin film of $\mathrm{Ne}$ condensed directly on the source. 
of its excellent potential yield from Ni in the INEL EBR-II fast breeder reactor, and partly due to the high specific activity attainable through chemical separation. The EBR-II reactor combined with the excellent hot cell and engineering capabilities, make INEL an ideal location for the ISPS. The possibility of using the INEL ATR thermal neutron reactor with other isotopes such as $\mathrm{Kr}, \mathrm{Cu}$, or $\mathrm{F}$ will also be studied as an alternative to the ${ }^{58} \mathrm{Co}$ approach.

In Year Two the INEL will continue work on a ${ }^{58} \mathrm{Co}$ chemical separation and deposition capability inside one of its hot cell areas, based on in-house experience as well as research and development in Ann Arbor. At Mount Holyoke, preliminary cryogenic tests will take place.

During Year Three the ${ }^{58} \mathrm{Co}$ Phase I ISPS device will be developed, tested, and operated. A "slow" monoenergetic positron beam of $\sim 10^{8}$ to $10^{10}$ $\mathrm{e}^{+} / \mathrm{s}$ at $5 \mathrm{keV}$ on a $\leq 0.03-\mathrm{cm}$-diameter target will be demonstrated. In the following year, depending on funding, a cryogenically moderated ISPS device at $10^{11} \mathrm{e}^{+} / \mathrm{s}$ will be pursued at INEL. Recent developments in ${ }^{58} \mathrm{Co}$ plating techniques at the University of Michigan are encouraging and indicate that this goal is not unrealistic. ${ }^{7}$ Concurrent to this ISPS device development effort, a "Super-Microscope" will be designed in collaboration with the Michigan Group. Issues critical to the coupling of the ISPS device to the "Super" Positron Microscope will also be investigated in Year Three.

The INEL has supported the preliminary research associated with the ISPS concept for the past several years with internal funds. ${ }^{9}$ The INEL intends to continue its support of the ISPS program during Year One through Three with supplemental internal funds and intends to subsidize irradiation, hot material handling, and hot cell costs, so that the ISPS demonstration program goals can be achieved within the budget requested.

The INEL ISPS concept has one possible spinoff that may benefit the entire positron community: that of providing Curie sources of ${ }^{58} \mathrm{Co}$ at low cost. This is by no means a certainty, as the INEL will have to decide if this is practical and desirable within its limitations of mission, budget, and potential benefit to the INEL. It is a possibility, however, that should not be overlooked when evaluating this concept in light of other concepts for intense beams, such as the proposed ${ }^{79} \mathrm{Kr}$ reactor based source. ${ }^{10}$ The used ${ }^{58} \mathrm{Co}$ from the main dish, which would normally be discarded, may be extremely useful to some research groups.

\section{CONCLUSION}

The INEL ISPS is a promising contender for a major positron facility which could serve the needs for the next generation of slow positron experiments. Using essentially a waste product produced in the reflectors of 
the EBR-II fast breeder reactor, the beam is economically attractive and is capable of producing extremely high slow positron rates, up to $10^{13} \mathrm{slow} \mathrm{e}^{+} / \mathrm{s}$, or $10^{12}$ slow $\mathrm{e}^{+} / \mathrm{s}$ over a $0.03 \mathrm{~cm}$ diameter. This intensity will allow a facility with multiple user ports for a variety of possible experimental arrangements that can be tailored to user needs and specifications.

1. A. P. Mills, Jr., Appl. Phys. 23, 189(1980).

2. J. Van House and A. Rich, Phys. Rev. Lett. 61, 488 (1988).

3. G. R. Brandes, K. F. Canter, T. N. Horsky, and A. P. Mills, Jr., Appl. Phys. 46, 335 (1988).

4. L. D. Hulett, J. M. Dale, and S. Pendyala, Mater. Sci. Forum 2, 133 (1984).

5. G. R. Brandes, K. F. Canter, and A. P. Mills., Jr., Phys. Rev. B 43, 10103(1991).

6. Refer to other papers on high intensity beams and applications in this volume.

7. H. Griffin et al. elsewhere in this volume.

8. B. L. Brown et al. elsewhere in this volume.

9. Eric H. Ottewitte, "High-Intensity Positron Beam Via 200 MW, LargeVolume, Test (Fission) Reactor", Proceedings of the BB Factory Workshop, January 27, 1988 (World Press). See also H. Mokowitz elsewhere in this volume.

10. A. P. Mills, Jr. Nuc. Sci. and Eng. 110, 165(1992). 